\title{
Effect of the Grain Sizes on the Ultrasonic Propagation and Attenuation on Different Types of Steels Microstructure During Non-Destructive Testing
}

\author{
Irida Markja $^{1 *}$, Klodian Dhoska $^{1}$, Dervish Elezi ${ }^{1}$, Reza Moezzi $^{2,3}$, Michal Petru $^{2}$ \\ ${ }^{1}$ Faculty of Mechanical Engineering, Polytechnic University of Tirana, Albania Mother Teresa No.4, 1001 Tirana, Albania \\ ${ }^{2}$ Institute for Nanomaterials, Advanced Technologies and Innovation, Technical University of Liberec, Liberec 46117, Czech \\ Republic \\ ${ }^{3}$ Faculty of Mechatronics, Informatics and Interdisciplinary Studies Technical University of Liberec, Liberec 46117, Czech \\ Republic
}

Corresponding Author Email: imarkja@fim.edu.al

https://doi.org/10.18280/acsm.450408

Received: 30 June 2021

Accepted: 12 August 2021

\begin{abstract}
Keywords:
non-destructive testing/NDT, microstructure, grain size, steel, UT, ultrasonic NDT propagation and attenuation, micro-hardness $H V$
\end{abstract}

\begin{abstract}
In this paper we have proposed an experimental study of the steel grains sizes effect on the shift frequency of the ultrasonic waves being propagated in steels. Ultrasonic testing has been used in most inspection services for different materials as non-destructive testing. The novelty of our research work has been focused on the investigation of the new method for determining microstructure evolution of metals by using ultrasonic signals in conjunction with changes in grain size and hardness of steels. Furthermore, we have studied the microstructure of steel types S355, S275, Corten B and S275N. The microstructure results of steels have shown the changes that have been undergone from thermal and mechanical processes by using the attenuation of ultrasound waves during non-destructive testing.
\end{abstract}

\section{INTRODUCTION}

During the last decades, Ultrasonic Testing has been widely used in many industrial applications. Recently, Albania as a developing country has used Non-destructive testing (NDT) for different steel materials. Ultrasonic NDT evaluation is based on exciting the sample with an ultrasonic beam and calculates or evaluates the reflected beam, transmitted, or scattered from discontinuities within the material such as grains, fractures, voids or the microstructure itself. Ultrasonic testing besides being used for detection of flaws or defects within the structures also is used for determining the components thickness as well as characterization of microstructure of different materials [1-3].

The structure of a material is related to its chemical composition, properties, processing of bulk and surface treatments and their performance [2-4]. Most of the information in relation to composition and processing to its mechanical properties of the materials has been realized through the study of the microstructure of these materials. Characterization and interpretation of microstructures requires an understanding of the processes through which different metal structures were created. Many physical properties and in particular the mechanical behavior of metallic materials depend on the microstructure [2-6].

To characterize the metallic material microstructure, ultrasonic velocity, attenuation, and backscattering can be used. Grain size, which usually is determined from optical photomicrographs, is one of important micro structural parameters that affect mechanical properties such as yield and tensile strength. Ultrasonic methods since they are fast and are nondestructive are very advantageous [3, 4]. To determine grain size, much work has been done using ultrasonic attenuation and/or backscattering [5]. Metals grain size has significant influence on metallic structure properties and its elastic deformation. Determination of grain size in material manufacturing and service is important for characterization of microstructure $[1,2,6-8]$. The mechanical waves created during Ultrasonic inspection were in the form of ultrasound and they have been transmitted and propagated through volume of parts or components which reflect when the waves meet with the existing interface such as flaws in the welds. There are some losses of ultrasound amplitude or acoustic attenuation, as the ultrasound is transmitted through the material, which results from heterogeneity, anisotropy, and different grain sizes of crystalline media that the ultrasound goes through $[1,2,9]$.

In our research work we have performed characterization technique for evaluation of micro-hardness, grain size and attenuation coefficients for the steels type S355, S275, Corten $\mathrm{B}$ and $\mathrm{S} 275 \mathrm{~N}$. The materials used in this research have been chosen due to the low cost and they are the mostly used materials from the industry in Albania. The effect of the grain size and other several microstructural parameters on the ultrasonic propagation has been evaluated in this article, for experimental low alloyed carbon steel. Furthermore, to obtain the data of the results, the attenuation coefficient follows the Rayleigh law for scattering and manifests a maximum at a frequency value that increases as the grain size decreases. The value of frequency akin to the attenuation maximum, converted in wavelength can be approximately compared as 3 - 4 times the average grain size $[1,2,7]$. Our research it is focused on the investigation of the novel method which will be elaborated in details next, for analyzing the effect of grain size and determining microstructure evaluation of metals using non destructive testing. 


\section{EXPERIMENTAL}

\subsection{Materials}

Samples used in this study are hot rolled steel plates S355, S275, Corten B and S275N with chemical composition shown in Table 1 that have been based on the European standards and recent research work [10-16]. Figure 1 depicts the dimension of the prepared samples which correspond to $160 \mathrm{~mm} \times 60 \mathrm{~mm}$ $x 30 \mathrm{~mm}$ for the analysis and characterizations of their microstructure with ultrasonic testing NDT.

Table 1. Chemical composition of samples used in this research

\begin{tabular}{ccccc}
\hline $\begin{array}{c}\text { Element } \\
\text { Content \% }\end{array}$ & $\begin{array}{c}\text { Sample 1 } \\
\text { S355 }\end{array}$ & $\begin{array}{c}\text { Sample 2 } \\
\text { S275 }\end{array}$ & $\begin{array}{c}\text { Sample 3 } \\
\text { Corten B }\end{array}$ & $\begin{array}{c}\text { Sample 4 } \\
\text { S275N }\end{array}$ \\
\hline $\mathrm{C}$ & 0.11 & 0.16 & 0.19 & 0.16 \\
$\mathrm{Si}$ & 0.29 & 0.19 & $0.30 / 0.65$ & 0.19 \\
$\mathrm{Mn}$ & 0.133 & 0.55 & $0.8 / 1.25$ & 0.55 \\
$\mathrm{P}$ & 0.012 & 0.001 & 0.035 & 0.001 \\
$\mathrm{~S}$ & 0.005 & 0.005 & 0.003 & 0.005 \\
$\mathrm{Al}$ & 0.035 & 0.034 & $0.02 / 0.06$ & 0.034 \\
$\mathrm{~N}$ & 0.007 & 0.006 & - & 0.006 \\
$\mathrm{Cr}$ & 0.007 & 0.002 & $0.4 / 0.65$ & 0.002 \\
$\mathrm{Cu}$ & 0.026 & 0.003 & $0.25 / 0.4$ & 0.003 \\
$\mathrm{Ni}$ & 0.1 & 0.002 & 0.4 & 0.002 \\
$\mathrm{Ti}$ & 0.001 & 0.005 & - & 0.005 \\
$\mathrm{~V}$ & 0.043 & 0.005 & $0.02 / 0.1$ & 0.005 \\
$\mathrm{Nb}$ & 0.001 & 0.001 & - & 0.001 \\
$\mathrm{Mo}$ & 0.001 & 0.005 & - & 0.005 \\
$\mathrm{~B}$ & 0.0008 & - & - & - \\
$\mathrm{Ca}$ & - & - & - & - \\
\hline
\end{tabular}
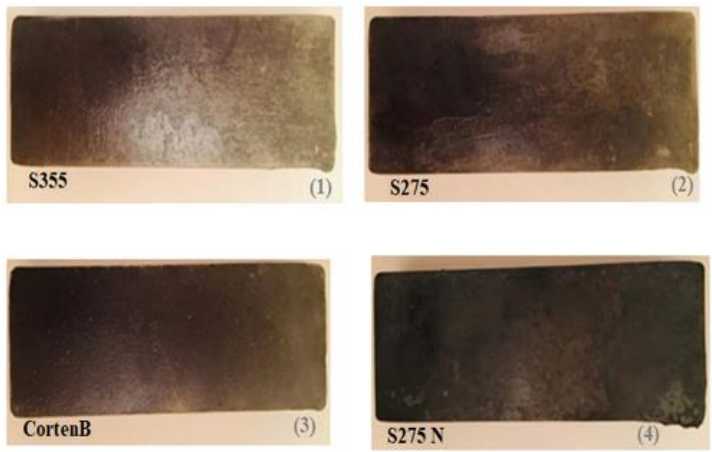

Figure 1. Steel Samples with dimensions 160mm $x$ 60mm $x$ $30 \mathrm{~mm}$

\subsection{Sample metallographic preparation}

Metallographic preparation of the samples and measurement are performed in Materials Science and Technology Laboratory, in Mechanical Engineering Faculty in Tirana-PUT, Albania [17].

As shown in Figure 2, the samples were cutted on small samples with dimensions $10 \mathrm{~mm} \times 10 \mathrm{~mm} \times 10 \mathrm{~mm}$, for examination on Optical Microscope to evaluate the shape, morphology, of grain sizes on steel microstructure during ultrasonic NDT testing.

Cutting of samples: Samples were cut into smaller size volumes, without any damage to microstructure changes and suitable to be used/analysed/examined in microscopes. The samples are cut with a low speed saw and water mixed with oil used for the cooler, to prevent the creation of heat for a thermal treatment of the sample surface.
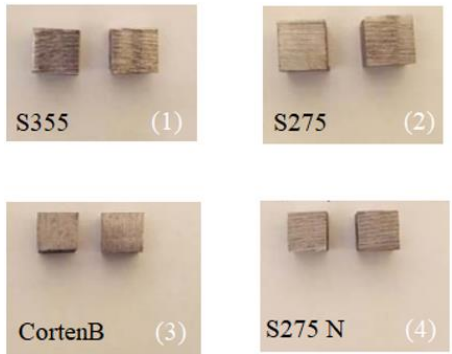

Figure 2. Cutting of samples

Coating of the sample with resin: This process protects the surface of the material, fills the gaps in damaged materials and improves the treatment of samples in irregular shape. The prepared samples were coated with resin according to the scheme in Figure 3.

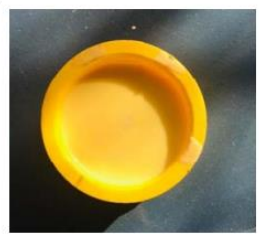

(a)

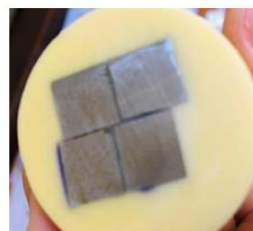

(b)

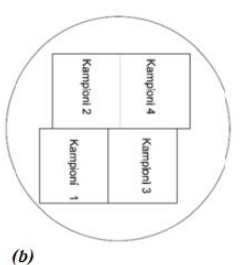

Figure 3. (a) Coating of the sample with resin, (b) samples placement scheme

Coarse Grinding: The grinding operation (Figure 4) was performed to remove the remaining scratch from the initial cutting of the samples with a saw. Grinding took place in two phases:

(a) Coarse grinding which was developed to prepare the initial flat surface;

(b) Medium and fine grinding at this stage it was possible to remove the scratch of the samples, orienting the samples perpendicular to the scratches. The papers used have granulometry 240, 400, 600, 800, 1200 and 2000 with abrasive silicon carbide $\mathrm{SiC}$ paper; also the speed of the grinding process was held into account to avoid overheating the sample.
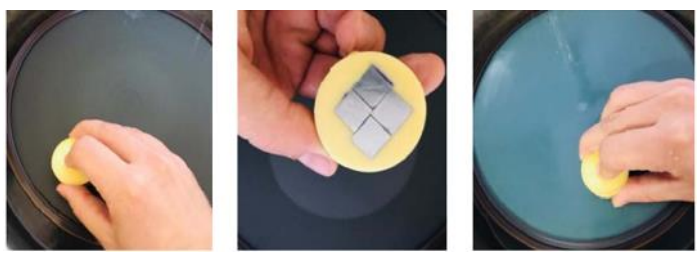

Figure 4. Grinding process

Mechanical Polishing: The final polishing process is used to remove surface damage, to polish it. Polishing involves the use of abrasives, the polishing process is aided by diamond abrasive particles $6 \mu$ which make the surface more clean as shown in Figure 5.
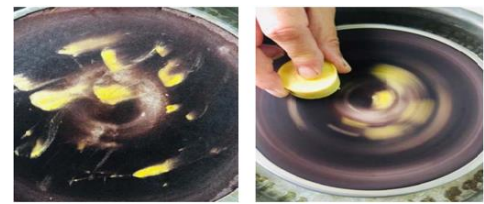

Figure 5. Polishing process 
Etching: The process as shown in Figure 6 was carried out with Nital $4 \%$, acid nitric $\mathrm{HNO}_{3}$ mixed with alcohol, for $15 \mathrm{sec}$ the samples were kept in the container with the nital solution, then dried and microscopic examination was performed for characterize the grains size of steel samples selected for this study.

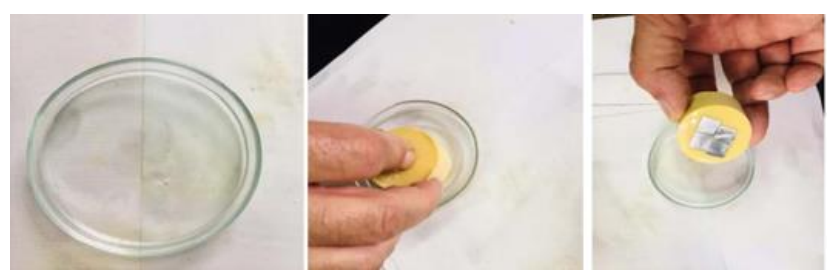

Figure 6. Etching process

\subsection{Characterization techniques}

Characterization techniques are:

1) Optical Microscope, Leica DMI $5000 \mathrm{M}$

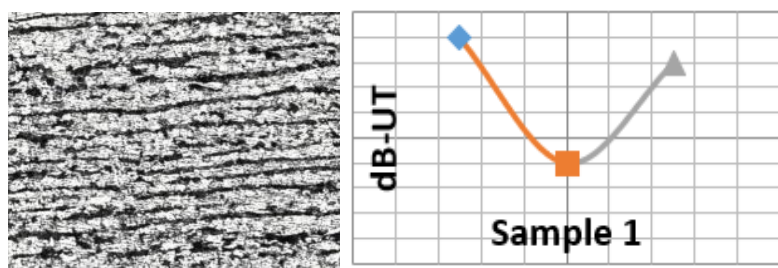

(a) Sample one

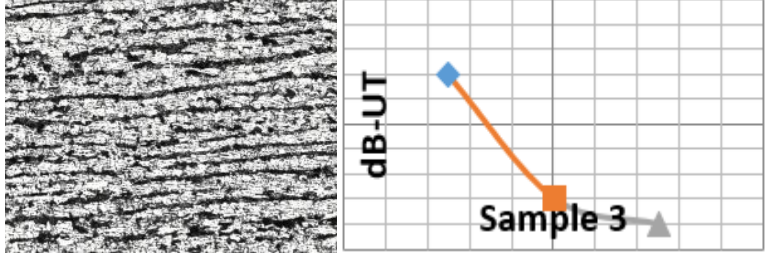

(c) Sample three
2) Micro-hardness Vickers HMV-2 tester

3) Ultrasonic Flow detector NDT

Performing micro-hardness Vickers (HMV-2 tester) on steel products with three different chemical compositions; then performing Optical Microscopy using Leica DMI 5000 M software for characterization of microstructure of samples/steel and for last Ultrasonic Propagation and Attenuation (MFD800C) was used.

\section{RESULTS}

\subsection{Optical microscope}

Figure 7 depicts the characterization of the microstructure carried on the hot rolled steel plates S355, S275, Corten B and $\mathrm{S} 275 \mathrm{~N}$ samples after heat treatment, normalizing. Observations of the microstructure were performed on the 200x and 400x metallographic optical microscope as well as the microhardness-Vickers with 400x magnification.

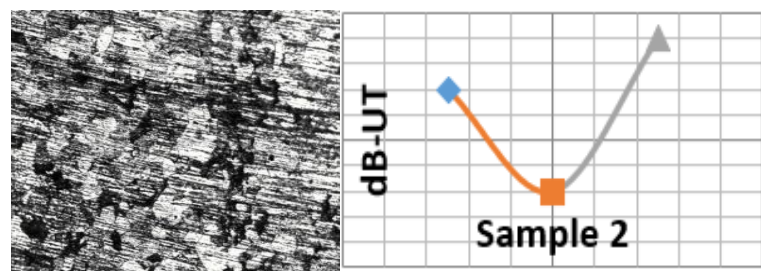

(b) Sample two

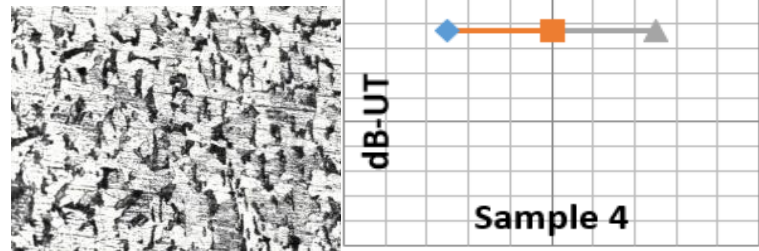

(d) Sample four

Figure 7. Attenuation coefficient as a function of grain size microstructure of samples with 200x magnification

Table 2. Measurement micro-Hardness HV0.2

\begin{tabular}{|c|c|c|c|c|c|c|}
\hline & \multicolumn{5}{|c|}{ Measurement micro-Hardness HV0.2 } & \multirow{2}{*}{ Average of measurement of micro-HV } \\
\hline & 1 & 2 & 3 & 4 & 5 & \\
\hline S355 (1) & 168 & 186 & 162 & 162 & 182 & 172 \\
\hline S275 (2) & 238 & 174 & 187 & 181 & 185 & 193 \\
\hline CortenB (3) & 182 & 184 & 145 & 154 & 146 & 162.2 \\
\hline $\mathrm{S} 275 \mathrm{~N}(4)$ & 145 & 156 & 151 & 159 & 145 & 151.2 \\
\hline
\end{tabular}

\subsection{Micro hardness Vickers}

The micro - hardness is in the range $151 \mathrm{HV}-193$ micro$\mathrm{HV}$ as an average of five measurements made for each sample. The micro - hardness of measurements are determined using the equipment "Micro-hardness Vickers HMV-2 tester," semiautomatic / automated which are calculated by optically measuring the diagonal lengths of the impression left by the indenter, with indentation time 10 seconds for each measurement. Figure 8 shows the micro-hardness Vickers HMV-2 tester during measurements.

The measurement parameters are selected according to the standard for evaluation of microhardness [17]. The applied force of measurement is $200 \mathrm{gf}$ (HV0.2) and the indentation time of applied force is 10 seconds. The measurements are measured and evaluated automatically by a semi-automatic device.

The Eq. (1) of micro hardness calculation is:

$$
H V=1.8544 \frac{P}{d^{2}}
$$

In the Figure 8 it is presented the Micro-hardness Vickers HMV-2 tester during measurement of steel samples used in this study, on the picture in right corner it is presented the value of the microhardness of samples S275N and on the right corner below it is presented the indenter of microVickers.

In Table 2 are presented the results of all measurements for samples: S355, S275, CortenB and S275N.

For each sample is evaluated five micro hardness in different points of the sample and then the average measurement value has been calculated. 

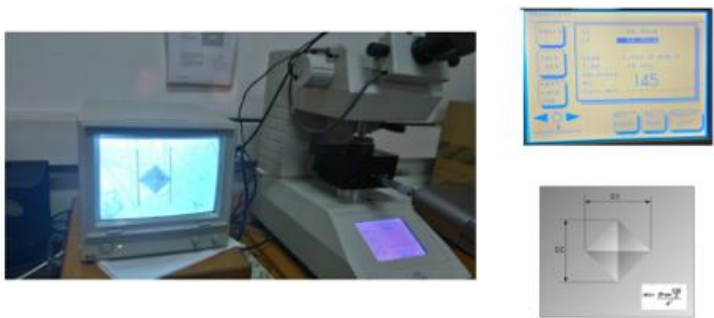

Figure 8. Micro-hardness Vickers HMV-2 tester during measurement

\subsection{Ultrasonic equipment, nondestructive testing}

Ultrasonic testing is one of the most useful non-destructive testing methods for inspection of fabricated structures and components $[1,6,7]$. Our ultrasonic transducer for ultrasonic testing is shown in Figure 9.

Attenuation is the term used to account for loss of wave amplitude or signal due to all mechanisms, including absorption, scattering, and mode conversion [2].

In our experimental work parameters of ultrasound testing are: sound waves at frequencies $f=2 \mathrm{MHz}$, and with crystal diameter $\mathrm{d}=10 \mathrm{~mm}$, with longitudinal waves. The distance sound traveled can be displayed on the Flow Detector. The screen can be calibrated to give accurate readings of the distance.

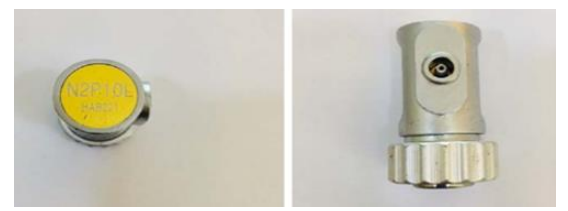

Figure 9. Ultrasonic Transducers for ultrasonic testing, NDT, $\mathrm{N} 2 \mathrm{P} 10 \mathrm{~L}$

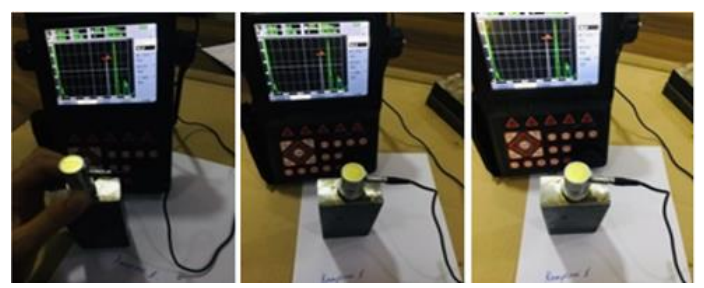

Figure 10. Measurement of ultrasound waves for sample 1

During the evaluation of the grain size, the same direction of the ultrasound wave was maintained against the direction of the sample texture. The direction of the measurement (ultrasound wave beam) is kept the same against the texture orientation in all samples to exclude the influence of texture on the final results. Figures 10 to 13 show the data gathered from the measurement of the samples with ultrasonic testing NDT.

Using the method mentioned above for each sample three measurements were done and the data gathered are shown and explained in Table 3. The wave frequencies used in this research work were $2 \mathrm{MHz}$ for each measurement. In the table below are presented the results of measurements for the samples S355, S275, CortenB and S275N. Ultrasonic velocity attenuation and backscattering can be used to characterize the microstructure of metals.

In Table 4 we have summarized the experimental results on the influence of grain size on the microstructure of some steels in the attenuation coefficient accompanied by the Vickers micro hardness evaluation (the values for each measurement of the samples are shown on Table 2).
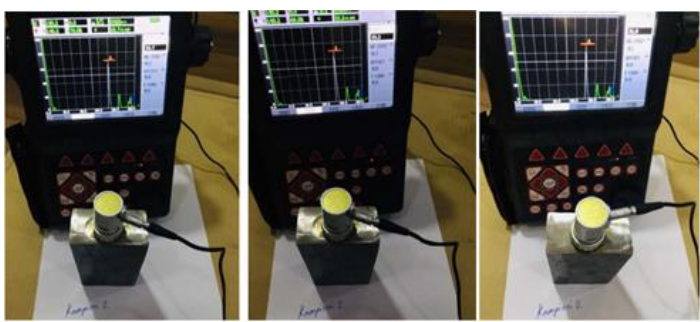

Figure 11. Measurement of ultrasound waves for sample 2

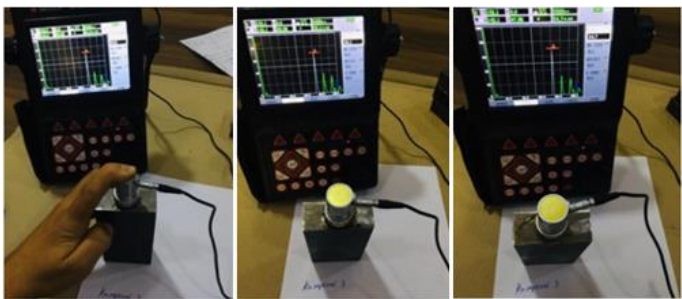

Figure 12. Measurement of ultrasound waves for sample 3
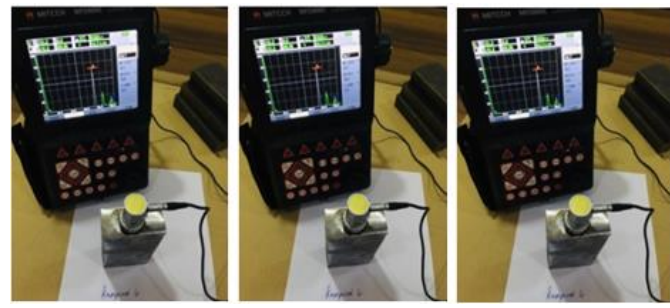

Figure 13. Measurement of ultrasound waves for sample 4

Table 3. Coefficient of attenuation for samples S355, S275, CortenB and S275N

\begin{tabular}{ccccc}
\hline \multicolumn{3}{c}{ Coefficient of attenuation (dB) } & Average of measurement of attenuation coef. (dB) \\
\hline S355 (1) & 41.4 & 40.9 & 41.3 & 41.2 \\
S275 (2) & 33.7 & 33.3 & 33.9 & 33.6 \\
CortenB (3) & 34.7 & 34.2 & 34.1 & 34.3 \\
S275N (4) & 34.7 & 34.7 & 34.7 & 34.7 \\
\hline
\end{tabular}

Table 4. Summarized of experimental results on the influence of grain size

\begin{tabular}{cccc}
\hline Samples & Grain Size $\mu \mathrm{m}$ Optical Metallographic Microscope & Coefficient of attenuation (dB) & Micro Vickers Hardness \\
\hline S275 & 9 & 33.6 & 193 \\
CortenB & 8 & 34.3 & 162.2 \\
S275N & 7.5 & 34.7 & 151.2 \\
S355 & 6 & 41.2 & 172 \\
\hline
\end{tabular}




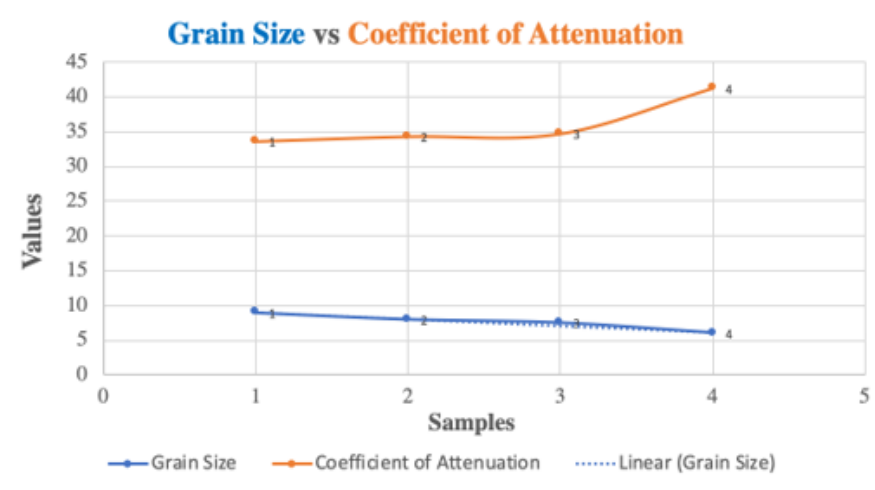

Figure 14. Grain Size $(\mu \mathrm{m})$ and Coefficient of attenuation $(\mathrm{dB})$

The experimental results of grains size evaluated with Optical Metallographic Microscope Leica DMI $5000 \mathrm{M}$ and the evaluation value of attenuation coefficient for samples used in this study are shown in the Figure 14 which explicitly shows that how the growth of the grain size of stainless steel can cause increasing of attenuation coefficient.

\section{DISCUSSION AND CONCLUSIONS}

In this research work we have studied the influence of grain size on ultrasonic propagation and attenuation during NonDestructive Testing. The attenuation coefficients tend to increase with larger grain size for stainless steel 355. Grain size influences ultrasonic velocities and attenuation, for example, with the increase of the grain size of stainless steel, the attenuation coefficient tends to increase.

It is possible to apply ultrasonic inspection to detect changes in grain size, microstructure, and mechanical properties of metal structures during service. The average grain size, as well as its influence on the propagation velocity and attenuation coefficient of ultrasonic waves, also affects the wave frequency propagating through the material.

This study provides an exact approach to quantitatively evaluate the grain size by investigating its relationship with the attenuation coefficient of ultrasonic non-destructive evaluation testing. The knowledge obtained from this study can be applied to monitor the material of many sorts of industrial structures in the future, such as pipes, pressure vessels, and power plants.

Future research work would reveal the effects of texture and grain boundaries on ultrasonic attenuation coefficients of steels.

\section{ACKNOWLEDGMENT}

This research work is a mutual collaboration between Albania and Czech Republic which is supported by Polytechnic University of Tirana, partially from the Ministry of Education, Youth and Sports of the Czech Republic and the European Union (European Structural and Investment Funds Operational Programme Research, Development and Education) in the frames of the project "Modular platform for autonomous chassis of specialized electric vehicles for freight and equipment transportation" Reg. No. CZ.02.1.01/0.0/0.0/16_025/0007293.

\section{REFERENCES}

[1] Bonifazi, F., Burrascano, P., Di Schino, A., Mengaroni, S., Petruci, F., Ricci, M., Senni, L. (2018). Ultrasonic NDT of steel: Effect of the grain size on the ultrasonic propagation and attenuation. Journal of Chemical Technology and Metallurgy, 53(23): 346-353.

[2] Guo, Y. (2003). Effects of material microstructure and surface geometry on ultrasonic scattering and flaw detection. Iowa State University.

[3] Sojiphn, K., Wangsupangkul, P., Chailampangsuksakul, T. (2018). Application of ultrasonic inspection for microstructure analysis of metals. The 10th International Conference on Materials Science and Technology, Bangkok, Thailand. https://doi.org/10.13140/RG.2.2.16419.30246

[4] Badidi Bouda, A., Aljohani, M.S., Mebtouche, A., Halimi, R., Djerir, W. (2011). Characterization of grains size by ultrasounds. In Key Engineering Materials, 482: 49-56.

https://doi.org/10.4028/www.scientific.net/KEM.482.49

[5] Saniie, J., Bilgutay, N.M. (1986). Grain size evaluation. Journal of the Acoustical Society of America, 80(6).

[6] Aghaie-Khafri, M., Honarvar, F., Zanganeh, S. (2012). Characterization of grain size and yield strength in AISI 301 stainless steel using ultrasonic attenuation measurements. Journal of Nondestructive Evaluation, 31(3): 191-196. https://doi.org/10.1007/s10921-0120134-Z

[7] Wan, T., Naoe, T., Wakui, T., Futakawa, M., Obayashi, H., Sasa, T. (2017). Effects of grain size on ultrasonic attenuation in type $316 \mathrm{~L}$ stainless steel. Materials, 10(7): 753. https://doi.org/10.3390/ma10070753

[8] Zhang, J., Song, Y., Li, X., Zhong, C. (2020). Comparison of experimental measurements of material grain size using ultrasound. Journal of Nondestructive Evaluation, 39(2): 39. https://doi.org/10.1007/s10921020-00675-4

[9] Bouda, A.B., Lebaili, S., Benchaala, A. (2003). Grain size influence on ultrasonic velocities and attenuation. NDT \& E International, 36(1): 1-5. https://doi.org/10.1016/S0963-8695(02)00043-9

[10] European Committee for Standartization, EN10204/2004. Metallic products - Types of inspection documents. https://standards.iteh.ai/catalog/standards/cen/541961b2 -83a5-4190-a21e-97d523a891e0/en-10204-2004.

[11] European Committee for Standartization, EN10025 2:2019. Hot rolled products of structural steels-Part2: Technical delivery conditions for non-alloy structural steels. https://standards.iteh.ai/catalog/standards/cen/c84f57d28035-43ac-81d2-b2237e0d8070/en-10025-2-2019.

[12] Dhoska, K. (2019). Tensile testing analysis of the HRB400 steel reinforcement bar. International Journal of Innovative Technology and Interdisciplinary Sciences, 2(3):

253-258. https://doi.org/10.15157/IJITIS.2019.2.3.253-258

[13] Zitelli, C., Napoli, G., Mengaroni, S., Di Schino, A. (2017). High strength vanadium micro-alloyed steels for forgings: Influence of quenching and tempering temperatures. Journal of Chemical Technology and Metallurgy, 52: 579-582.

[14] Choi, S., Ryu, J., Kim, J., Jang, K. (2019). Comparison of linear and nonlinear ultrasonic parameters in 
characterizing grain size and mechanical properties of 304L stainless steel. Metals, 9(12): 1279. https://doi.org/10.3390/met9121279

[15] Koça, O., Sulejmani, A., Dhoska, K. (2021). Pressure distribution on rolling-slide contact problem. Pollack Periodica, 16(1): 71-76. https://doi.org/10.1556/606.2020.00272

[16] Bai, X., Zhao, Y., Ma, J., Liu, Y., Wang, Q. (2018).
Grain-size distribution effects on the attenuation of lasergenerated ultrasound in $\alpha$-titanium alloy. Materials, 12(1): 102. https://doi.org/10.3390/ma12010102

[17] Markja, I., Dhoska, K., Elezi, D. (2019). Surface treatments and coatings application on the aluminum products. International Scientific Journal Materials Science, Non-Equilibrium Phase Transformations, 5(1): 26-27. 